\title{
BMJ Open Screening and prevention for latent tuberculosis in immunosuppressed patients at risk for tuberculosis: a systematic review of clinical practice guidelines
}

\author{
Tasnim Hasan, ${ }^{1}$ Eric Au, ${ }^{2}$ Sharon Chen, ${ }^{1,3}$ Allison Tong, ${ }^{4,5}$ Germaine Wong ${ }^{2,5}$
}

To cite: Hasan T, Au E, Chen S, et al. Screening and prevention for latent tuberculosis in immunosuppressed patients at risk for tuberculosis: a systematic review of clinical practice guidelines. BMJ Open 2018;8:e022445. doi:10.1136/ bmjopen-2018-022445

- Prepublication history and additional material for this paper are available online. To view these files, please visit the journal online (http://dx.doi. org/10.1136/bmjopen-2018022445).

Received 18 February 2018 Revised 15 July 2018 Accepted 25 July 2018
Check for updates

(C) Author(s) (or their employer(s)) 2018. Re-use permitted under CC BY-NC. No commercial re-use. See rights and permissions. Published by BMJ.

For numbered affiliations see end of article.

Correspondence to Dr Tasnim Hasan; tasnim.hn@gmail.com

\section{ABSTRACT}

Objective Immunosuppressed individuals are at a high risk of latent tuberculosis infection (LTBI) and clinical practice guidelines for the screening and management of LTBI in at-risk patients have been developed. We assessed the scope, quality and consistency of clinical practice guidelines on screening for LTBI and the prevention of tuberculosis infection (TB) in high-risk patient populations. Design We conducted a systematic review of clinical practice guidelines. Methodological quality of these guidelines was assessed using the Appraisal of Guidelines for Research and Education (AGREE) II instrument. Textual synthesis was used to summarise and compare the recommendations.

Data sources Electronic databases (MEDLINE, EMBASE, PsycINF0) and guideline registries were searched from inception to December 2017.

Results Thirty-eight guidelines were included. Nineteen focused on patients receiving medical immunosuppression, seven on transplantation, three on patients with HIV and nine were generalised across all at risk populations. Most guidelines $(n=32,84 \%)$ used a systematic approach to identify and appraise the evidence. The methodological quality of the guidelines varied with the overall mean AGREE II scores ranging from $35 \%$ to $80 \%$. Guidelines performed poorly in terms of editorial independence (average score $35 \%$, range $0 \%-92 \%$ ); however, most were robust in defining their scope and purpose (average score $80 \%$, range 56\%-100\%). Guidelines recommended either or both the tuberculin skin test and the interferon gamma release assay for screening. Treatment of LTBI with isoniazid was consistently recommended.

Conclusion Clinical practice guidelines on LTBI vary in quality and scope. The recommendations for screening varied across guidelines, while recommendations for treatment were largely consistent. Improving the consistency and quality of guidelines may help to optimise the screening and management of LTBI for improved patient outcomes.

\section{INTRODUCTION}

Immunosuppression increases the risk of reactivation of prior infection with
Strengths and limitations of this study

- This study systematically reviewed published clinical practice guidelines for screening and management of latent tuberculosis infection in immunosuppressed patients.

- We used the Appraisal of Guidelines for Research and Evaluation II instrument, an internationally validated tool, to assess the quality of the guidelines.

- We included 38 guidelines and 11 non-English guidelines were excluded, with only few guidelines published in low-resource settings.

Mycobacterium tuberculosis leading to tuberculosis (TB) disease. In high-income countries, the baseline risk of reactivation of latent TB infection (LTBI) varies between 6 and 20 per 100000 persons per year. ${ }^{12}$ The magnitude of the risk of TB reactivation among those who are immunosuppressed varies depending on the types of immunosuppression. The excess risk is highest among solid organ transplant recipients, particularly in lung (15-fold higher compared with the general population $)^{3}$ and stem cell transplant recipients (6-10-fold higher), ${ }^{4}$ followed by recipients of tumour necrosis factor (TNF) antagonists (5-7-fold higher) ${ }^{5-8}$ The risk of $\mathrm{TB}$ reactivation in patients with HIV infection is 3-20 times higher than the general population ${ }^{10}$ and causes up to $25 \%$ of deaths in these patients. ${ }^{9}$

Early detection of LTBI through screening of patients at increased risk for TB may provide a window of opportunity for interventions such as treatment to prevent the development of active TB. Screening often involves the use of the commercially available tuberculin skin test (TST) and an interferon gamma release assay (IGRA). IGRAs include the QuantiFERON-TB Gold Plus (Cellestis, Australia) and the T-SPOT test 
(Oxford Immunotec, UK). However, there are potential drawbacks associated with screening. False negative results $\left(2.8 \%\right.$ in one setting $\left.{ }^{11}\right)$ with attendant false assurance may lead to late or missed diagnoses and delayed treatment. Conversely, false positive results may lead to unnecessary and inappropriate investigations which may be harmful. ${ }^{12}$ There is also a lack of a valid and accurate reference standard for diagnosing LTBI in immunosuppressed populations, rendering the true test performance characteristics of IGRA difficult to ascertain.

To advise health practitioners, clinical practice guidelines have provided evidence-based recommendations that inform practitioner and patient decisions about appropriate healthcare for specific clinical circumstances. ${ }^{13}$ As such, guidelines on screening for LTBI and treatment in at-risk populations have been developed in various healthcare settings. However, it is unclear if these recommendations may be generalisable to others or if there is variability. Therefore, this review aims to assess and compare the rationale, scope, quality and consistency of clinical practice guidelines and consensus statements for the screening of LTBI, as well as for treatment against LTBI in immunosuppressed individuals.

\section{METHODS}

\section{Selection criteria}

Evidence-based clinical practice guidelines and consensus statements on screening for LTBI and treatment for LTBI in immunosuppressed individuals published in English were eligible for inclusion. Patients who were medically immunocompromised (including chemotherapy, disease modifying agents and biological therapy), had received a solid organ or stem cell transplant or HIV positive were included. Draft or unpublished guidelines, conference or discussion papers, opinions and guidelines and consensus statements replaced by updated and/or revised recommendations were excluded.

\section{Literature search}

We searched MEDLINE, Embase and PsycINFO from database inception to December 2017. Medical Subject Heading (MeSH) terms and text words for 'tuberculosis', 'immunosuppressed' and 'immunocompromised' were combined with terms relating to clinical practice guidelines and consensus statements (online supplementary appendix 1). Clinical guideline registries and reference lists were searched for additional clinical practice guidelines. Titles and abstracts were reviewed by two authors (TH and EA), and those which did not meet the inclusion criteria were excluded. Full text versions of potentially relevant guidelines or consensus statements were examined for eligibility.

\section{Appraisal of guidelines and consensus statements}

The methodological quality was assessed independently by $\mathrm{TH}$ and EA, using the Appraisal of Guidelines for Research and Evaluation II (AGREE II) instrument. ${ }^{14}$
AGREE II is an internationally validated, rigorously developed 23-item tool used to evaluate independent domains of guideline development including: scope and purpose, stakeholder involvement, rigour of development, clarity and presentation, applicability and editorial independence. Each item was rated on a seven-point scale ranging from strongly disagree (score 1) to strongly agree (score 7). The domain score was obtained by summing all scores of the individual items per domain and then standardising the total as a percentage of the maximum possible score for that domain:

\section{obtained score-minimum possible score maximum possible score-minimum possible score}

The minimum possible domain score would be the number of questions multiplied by the number of appraisers, multiplied by 1 (strongly disagree). The maximum possible domain score is the number of questions multiplied by the number of appraisers, multiplied by 7 (strongly agree). The AGREE scores were rated independently for each guideline by $\mathrm{TH} / \mathrm{EA}$ and a quadratic weighted kappa $(\kappa)$ score for each guideline and across all guidelines were calculated as a measure of inter-rater agreement. An overall weighted kappa was also calculated across all guidelines.

\section{Textual synthesis}

All text from each guideline were entered into the HyperRESEARCH software (ResearchWare 2011, V.3.0.3, Randolph, Massachusetts, USA) for storing, coding and searching textual data. Data were categorised by subheadings based on immunosuppression modality and by screening and treatment methods. Subsequently, we conducted a textual descriptive synthesis to analyse the content, consistency and evidence base of the recommendations.

\section{Patient and public involvement}

There was no patient or public involvement in this study.

\section{RESULTS}

\section{Characteristics of clinical practice guidelines}

We included 38 guidelines (figure 1) published from 2002 to 2017. These guidelines focused on medical immunosuppression (19 guidelines), ${ }^{1}{ }^{15-32}$ solid organ and stem cell transplantation (seven guidelines) ${ }^{3} 33-38$ and in HIV settings (three guidelines). ${ }^{9340}$ Nine were general guidelines which were not specific to a particular patient group and covered the detection of LTBI and its management. ${ }^{10}{ }^{41-46}$ These guidelines were published across 16 different countries from regions including North America, Western Europe, Asia, Australia and South Africa. A summary of the guideline characteristics is provided in table 1 .

Of the guidelines that discussed medical immunosuppression, nine provided recommendations for treatment across various medical specialties including dermatology, rheumatology, gastroenterology and respiratory 


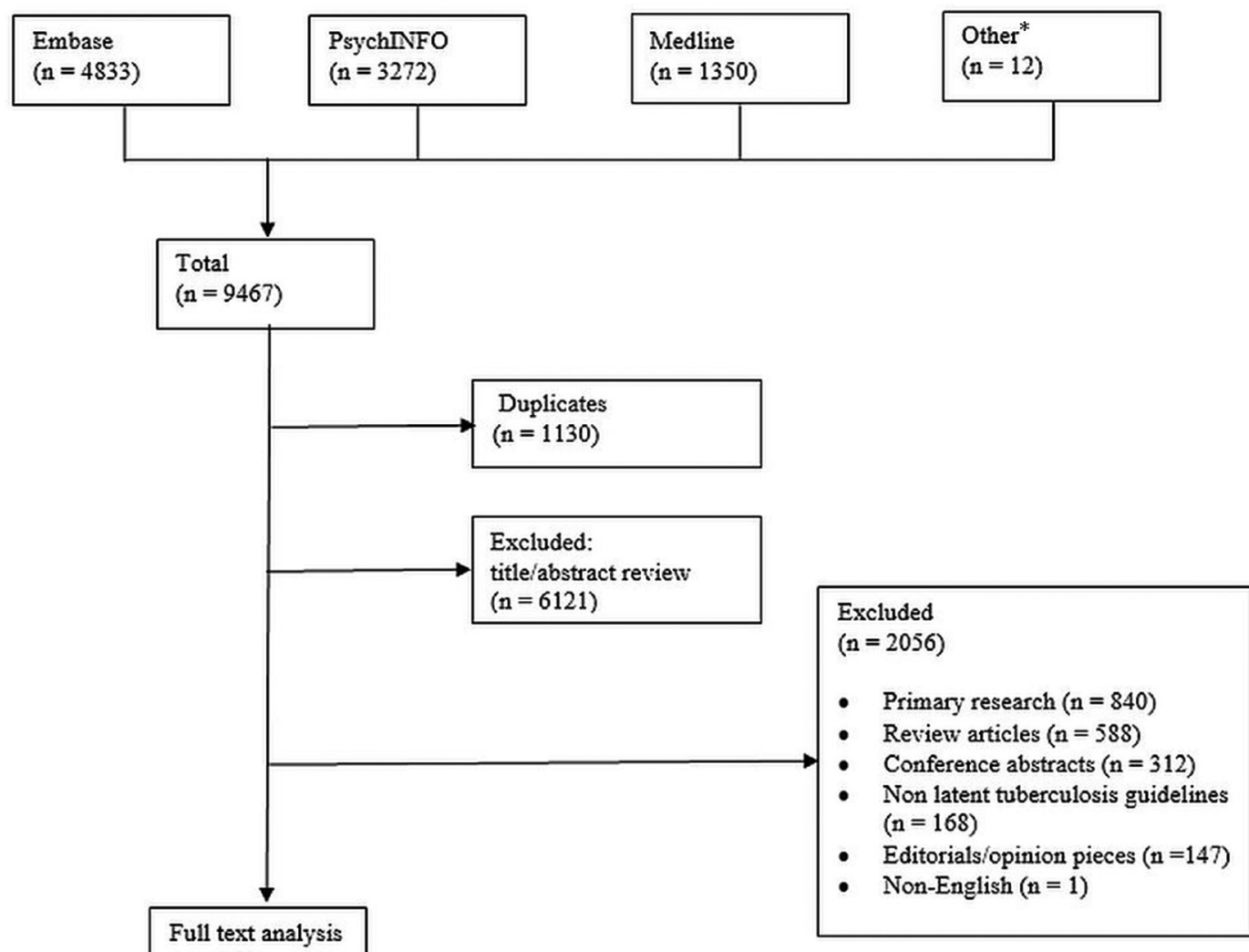

\section{Excluded}

$(\mathrm{n}=122)$

- Review articles $(n=52)$

- Primary research $(n=24)$

- Non latent tuberculosis guidelines ( $\mathrm{n}=23$ )

- Non English $(n=11)$

- Editorials/opinion pieces $(n=6)$

- Updated guidelines $(n=4)$

- Conference abstracts $(n=2)$

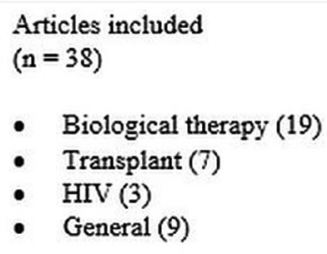

* Articles from references, other online databases

Figure 1 Database search strategy The medical databases EMBASE, PsychINFO and Medline were searched for articles relevant to tuberculosis in an immunosuppressed setting, using the search strategy described in online supplementary appendix 1. A total of 9467 articles were found and compiled into the EndNote software (Clarivate Analytics 2017, V.X7), of which 1130 articles were duplicate articles. From the remaining articles, 6121 articles were excluded by abstract review, primarily because they were irrelevant. A further 2056 articles were removed during a second review of titles and abstracts. A total of 160 articles were reviewed in full of which 122 were excluded as they did not fulfil guideline or relevance criteria. A total of 38 articles were included in our final review.

medicine. ${ }^{151618212426282931}$ Four were specific to patients with rheumatoid arthritis, ${ }^{20} 232527$ of which one focused only on patients receiving infliximab, ${ }^{23}$ while two guidelines were specific to patients with psoriasis. ${ }^{18} 30$ One guideline focused on patients with rheumatological or gastroenterological disease. ${ }^{15}$ There were specific guidelines addressing inflammatory joint disease,${ }^{19}$ rheumatological disease ${ }^{1}$ and autoimmune bullous diseases. ${ }^{22}$ One guideline discussed patients at risk due to methotrexate therapy. ${ }^{32}$ Of the transplantation guidelines, two guidelines were for kidney transplantation, ${ }^{34}{ }^{36}$ one for stem cell transplantation, ${ }^{38}$ one for both solid organ and 


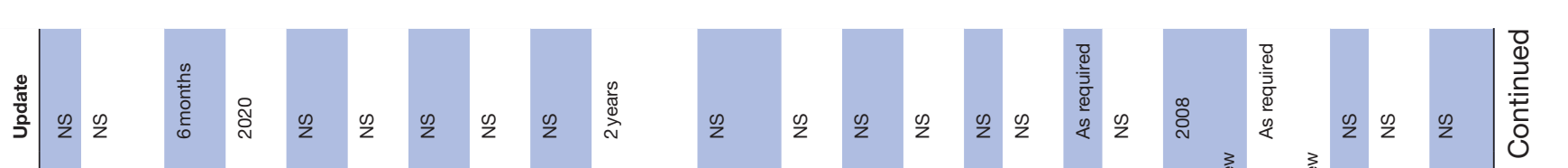

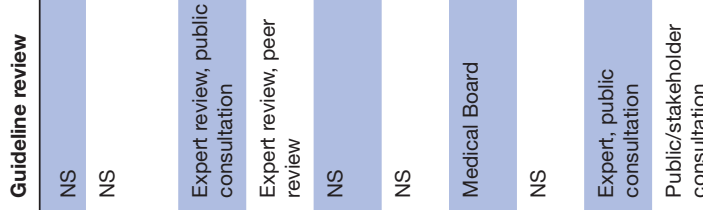

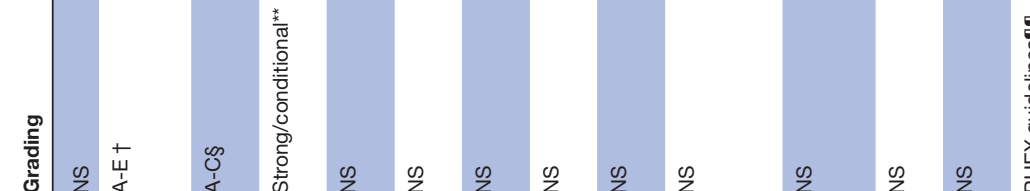

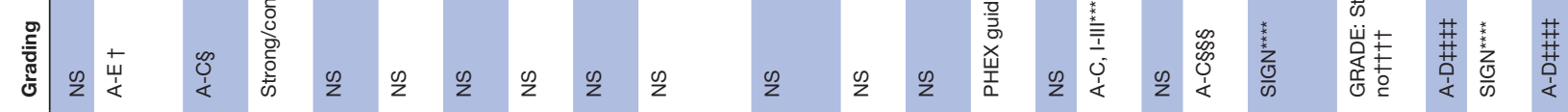

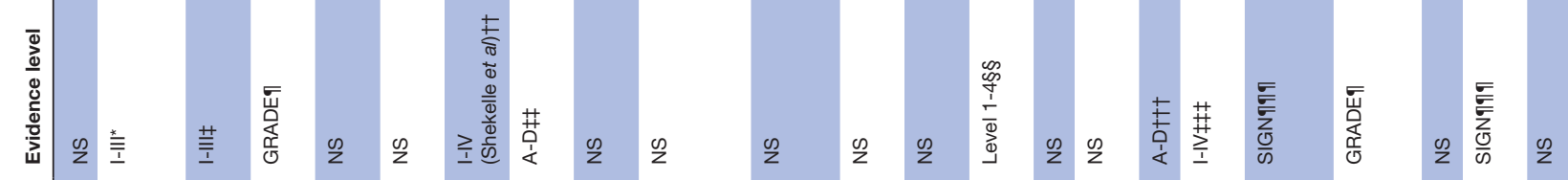

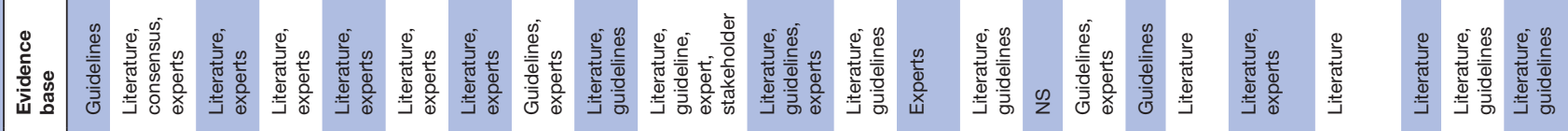

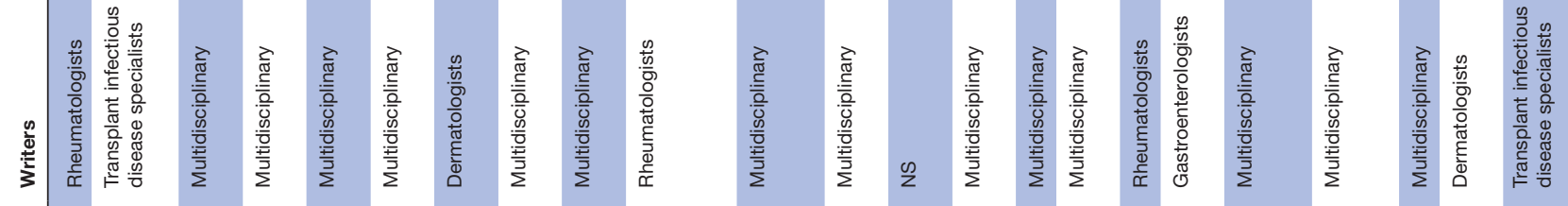

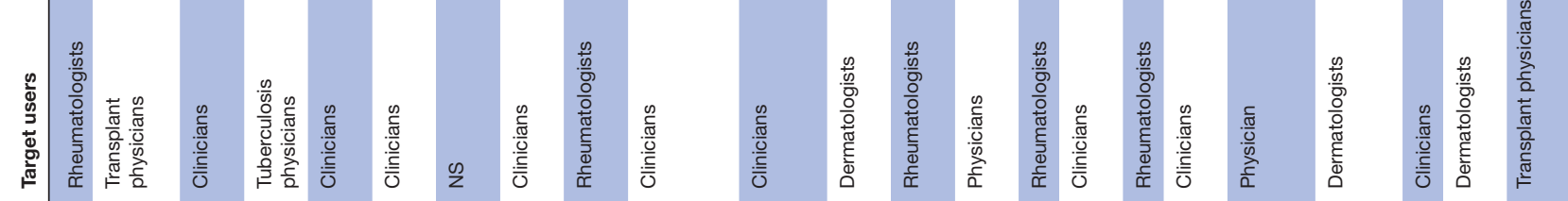

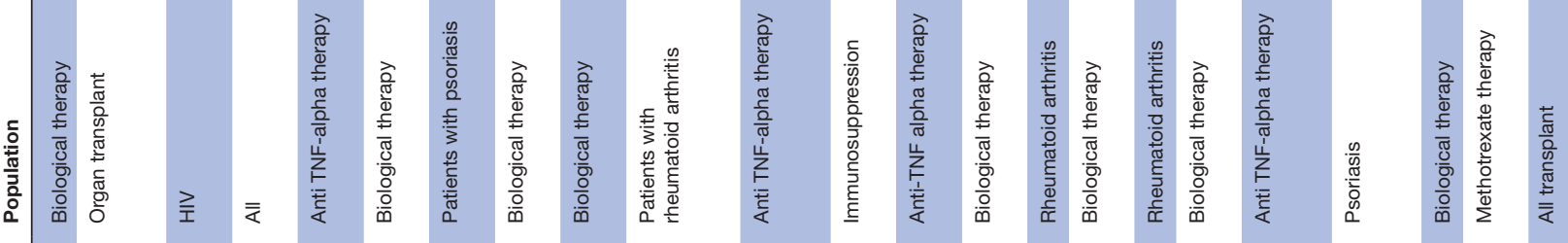

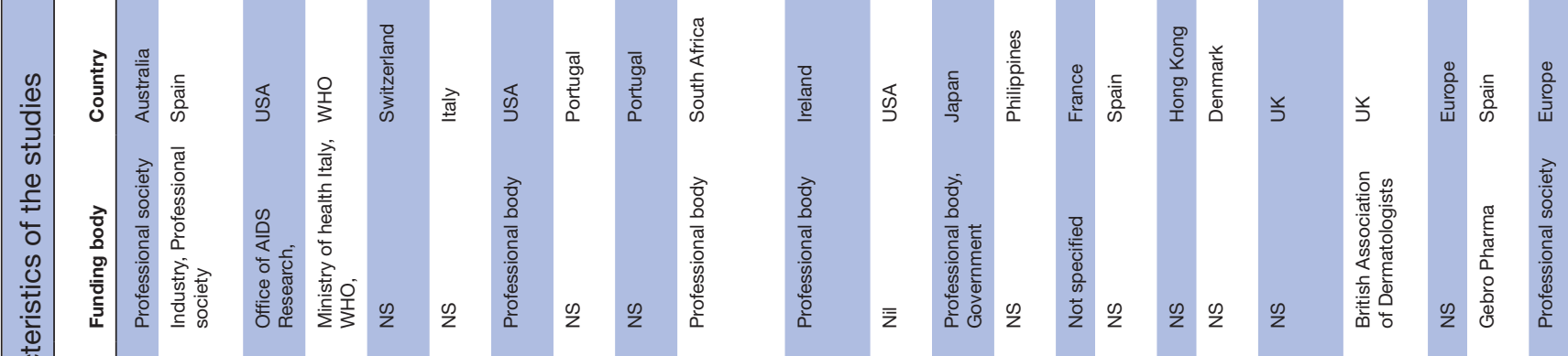

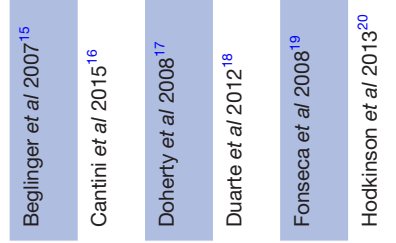

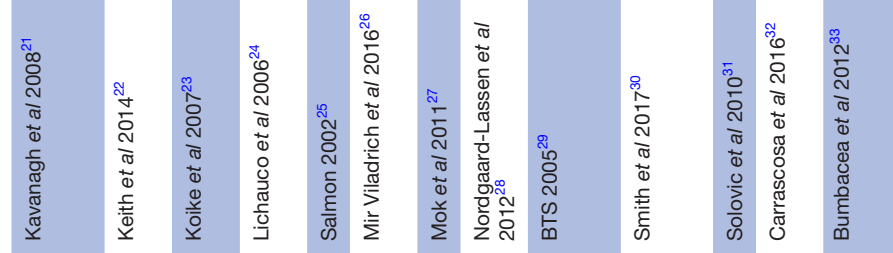




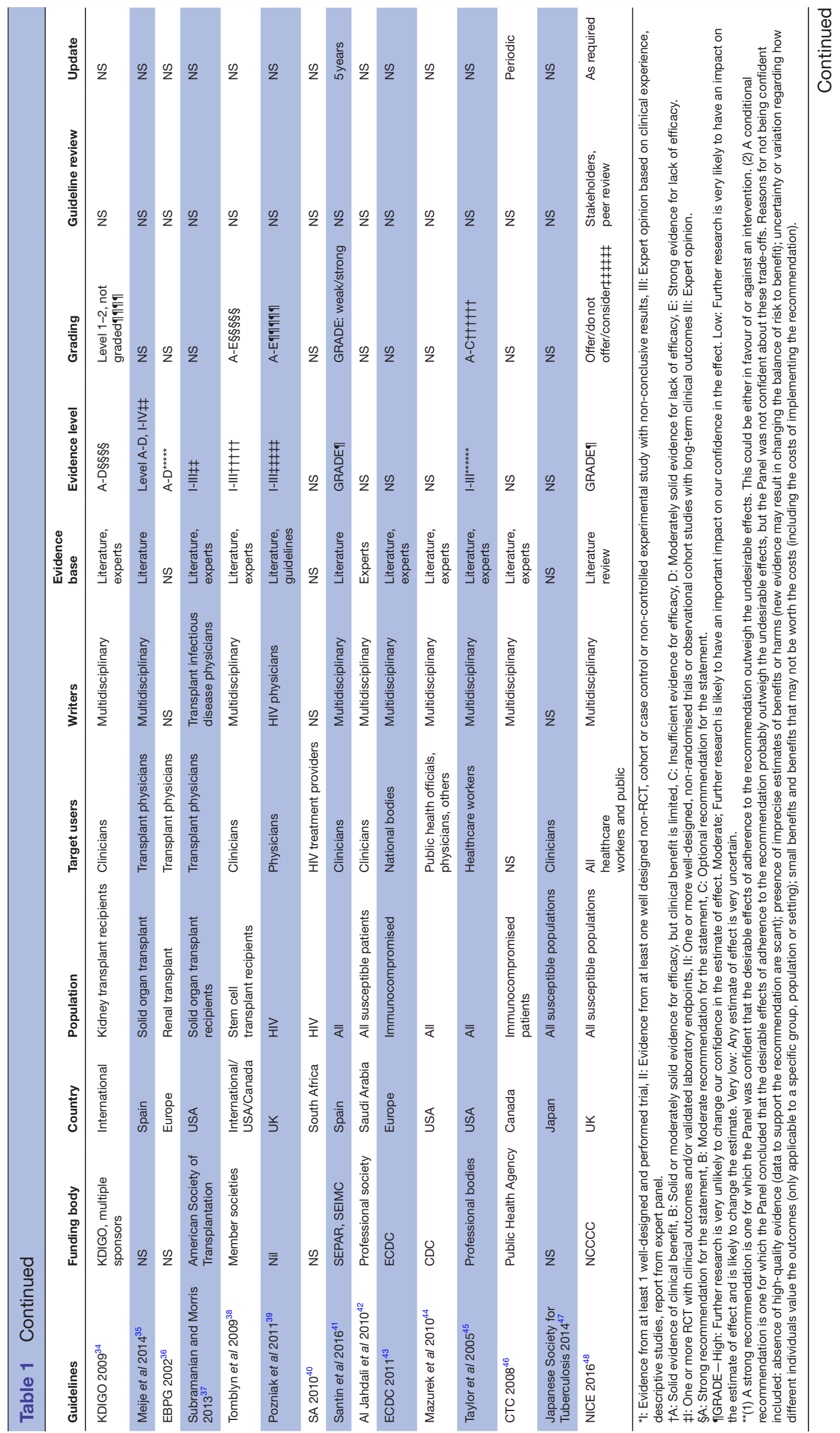

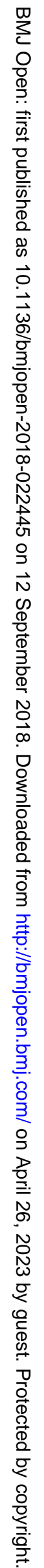




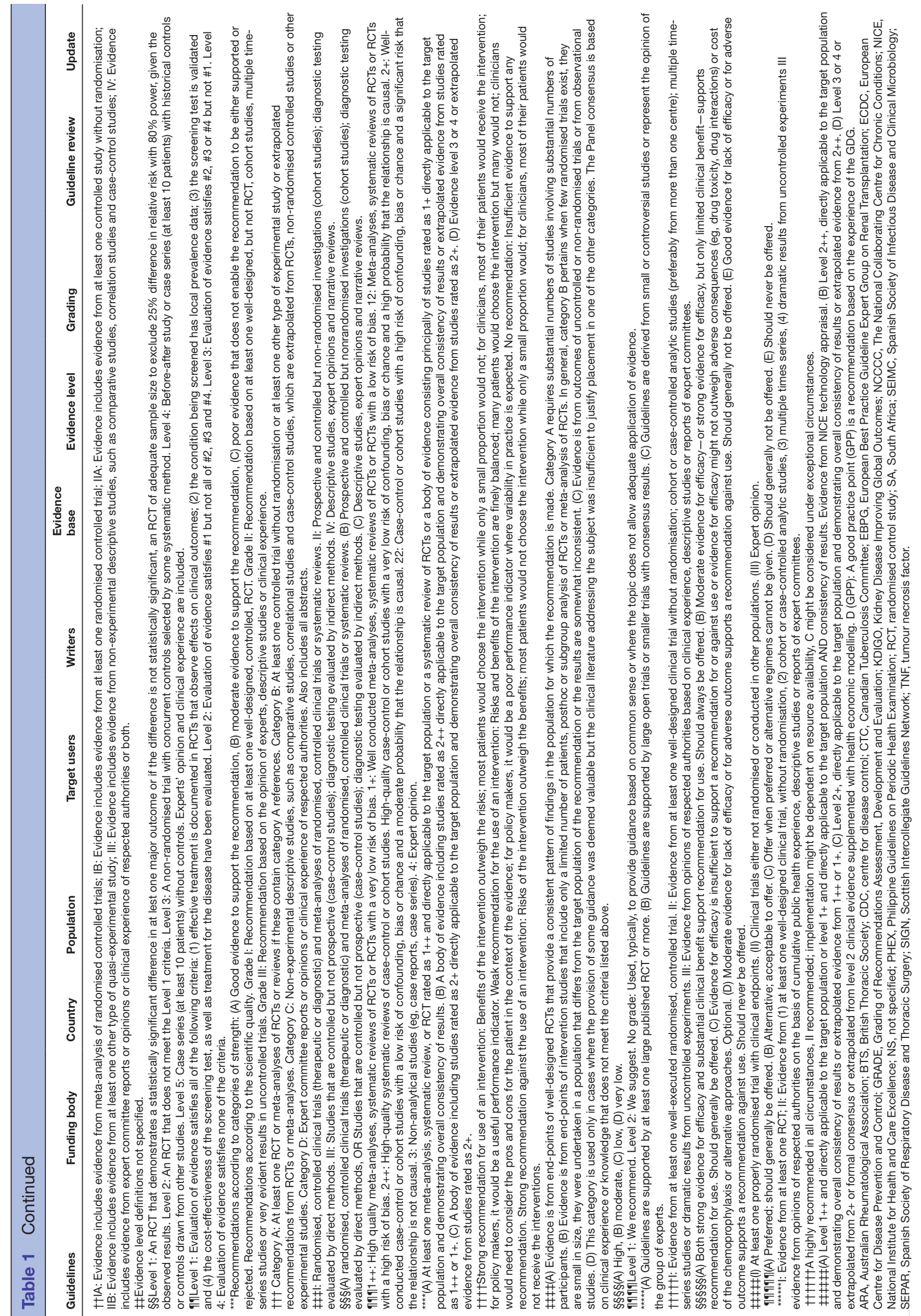


stem cell transplantation ${ }^{33}$ and three for all forms of solid organ transplantation. ${ }^{3} 3537$

Three guidelines addressed LTBI in patients with HIV. ${ }^{93940}$ There were nine other guidelines which discussed screening in all at risk populations. ${ }^{10-48}$ Six of these also included discussion on patients with $\mathrm{HIV}^{41-4547}$ and four were IGRA specific guidelines, although these guidelines also used TST as part of their screening strategies. ${ }^{41} 434446$ Three guidelines were developed in countries with a high prevalence of TB (South Africa and Philippines). ${ }^{20} 2440$

Across the guidelines, the methods for literature review were not always specified. Literature review was conducted in 32 guidelines $(84 \%),{ }^{1} 391015-22$ 24 26-35 37-39 41-46 48 of which 12 based their recommendations on a combination of the literature review and expert consensus. ${ }^{391015-1820212629343743-46}$ Two guidelines were based on expert consensus alone. ${ }^{23} 42$ Twenty guidelines graded the level of evidence. ${ }^{3910} 171824$ 27-30 32 34-3942 4648 Furthermore, 17 guidelines graded the strength of their recommendations. ${ }^{3910242628-343839414548}$ Where evidence was graded, it was often of low quality. Only nine (24\%) guidelines were peer reviewed, ${ }^{9} 1017192024293048$ with five (13\%) made available for public consultation prior to publication. ${ }^{9} 19202448$ Only one guideline included a formal cost-effectiveness analysis ${ }^{48}$ which suggested that TST was more cost effective compared with the IGRA. The incremental cost-effectiveness ratio was influenced by prevalence of disease and age of the patients.

\section{Methodological quality}

Table 2 summarises the AGREE domain scores of each guideline. The mean AGREE score (and range) for all guidelines was $55 \%(0 \%-100 \%)$. In terms of scope and purpose, on average $80 \%(56 \%-100 \%)$ of criteria were met for all guidelines. The average score for stakeholder involvement was $51 \%$ (11\%-97\%), for rigour of development $47 \%$ $(10 \%-93 \%)$, clarity and presentation $74 \% \quad(50 \%-92 \%)$, applicability $47 \%(0 \%-92 \%)$ and editorial independence $35 \%(0 \%-92 \%)$. The overall domain mean score was $55 \%$ $(35 \%-80 \%)$.

Weighted Kappa scores $(\kappa)$ to assess inter-rater agreement ranged from a score between poor to very good, with the majority being moderate $(0.41-0.60)$ to very good (0.81-1.00). The overall weighted score was 0.65 (95\% CI $0.60-0.69)$, with good concordance between reviewers. The AGREE scores did not improve with later guidelines and over time.

\section{Textual synthesis}

A summary of the guidelines and the recommendations are provided in table 3. Most guidelines recommended screening in all immunosuppressed patients, and treatment if there was clinical evidence of LTBI.

\section{Screening for latent TB infection \\ Populations of interest}

Most clinical practice guidelines recommended screening for LTBI in patients starting immunosuppression or were highly likely to start immunosuppression, and patients immunosuppressed due to concurrent illness, including patients with HIV and/or undergoing solid organ and bonemarrow transplantation. ${ }^{315-20} 222426333537394748$ Although medical immunosuppression was mostly biological therapy, two guidelines specified recommendations for patients who have received medical immunosuppression such as methotrexate, ${ }^{1732}$ cyclosporine and $\mathrm{T}$ cell blocking agents for the management of autoimmune disease. ${ }^{17} \mathrm{~A}$ third guideline which considered all immunosuppressed patients also specified the use of non-biological therapies. ${ }^{47}$

\section{Screening modalities and frequencies}

A combination of TST and/or IGRA testing, chest X-ray, detailed background history (including previous exposure to other individuals with TB) and risk factor assessment (travel or migration from endemic areas) was the most frequent recommendation for LTBI screening in immunosuppressed individuals. ${ }^{1} 17182123242629-3247$ The recommended choice of screening modalities and their frequency were reliant on test availability and costs. The TST is widely available and economical. ${ }^{10}$

In guidelines pertaining to medical immunosuppression, the recommendations for screening varied considerably between the use of TST and IGRA. Concurrent testing with both TST and IGRA was supported in six guidelines, ${ }^{16} 1820222632$ however, three recommended the use of IGRA alone. ${ }^{1528} 30$ Seven guidelines supported TST screening alone, but these recommendations were published prior to 2011. ${ }^{17192123242729}$ Two other guidelines recommended the use of either the TST or IGRA. ${ }^{122}$ In addition, two other guidelines recommended IGRA for BCG vaccinated individuals. ${ }^{16} 17$

In patients who require long-term maintenance medical immunosuppression, repeat testing at yearly intervals using IGRA was recommended by three guidelines, ${ }^{172831}$ but two advocated against this, as the benefits of frequent IGRA screening was questionable. ${ }^{1627}$ IGRA was recommended by one guideline in the presence of (any) skin disease due to difficulties in inoculating the TST in many of these cases. ${ }^{18}$

For transplant recipients, those with HIV and other immunosuppressed individuals, most guidelines acknowledged the added value of including TST and IGRA in the screening algorithm. ${ }^{9} 1033$ 35 37-39 41-46 48 Two guidelines specified the preference for IGRA over TST as the standard triage screening tool for LTBI, because of the high false positive rates associated with $\mathrm{TST},{ }^{34}$ particularly among those who had been vaccinated with BCG. ${ }^{47}$ However, across all guidelines, among BCG vaccinated individuals, two guidelines recommended a two-step strategy for screening LTBI. ${ }^{31} 42$ TST was often considered as the triage test. If negative, IGRA was recommended as the second test to confirm the diagnosis. This has also been recommended to increase case detection in five other guidelines. ${ }^{1720303546}$

Costs were also considered as a key factor in determining the frequency and modality of screening in immunosuppressed individuals. The WHO have suggested IGRA and/or TST may be used in high-income and upper-middle-income 


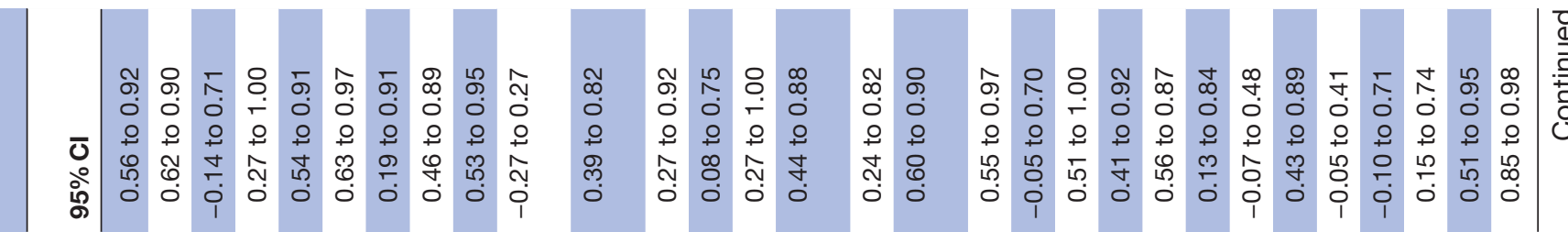

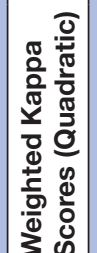

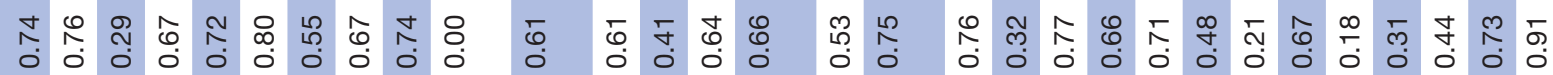

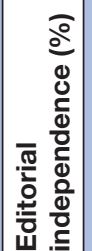

$\circ \underset{\sim}{\infty} \infty_{\infty}^{\infty}$ $\frac{0}{0}$
$\frac{2}{2}$
$\frac{0}{0}$
$\frac{0}{0}$
$\frac{0}{2}$
$\frac{0}{4}$

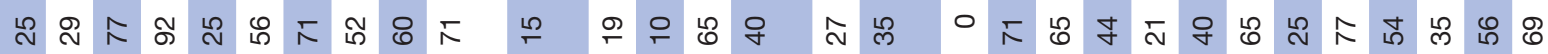

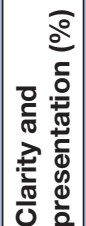

$\hat{0} \mathfrak{N}$

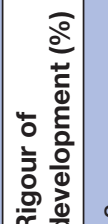

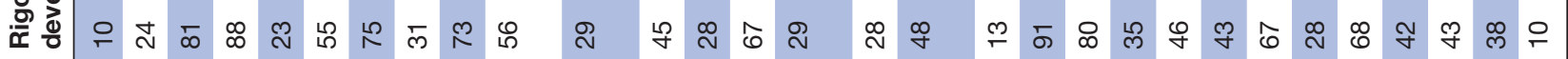

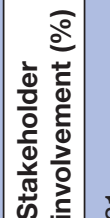

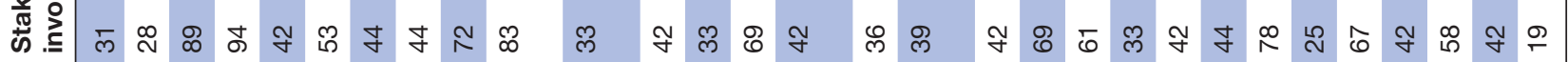

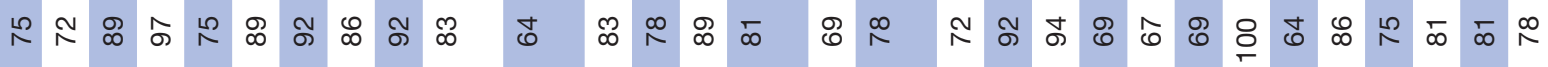

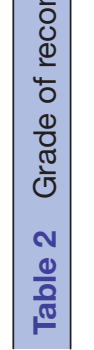

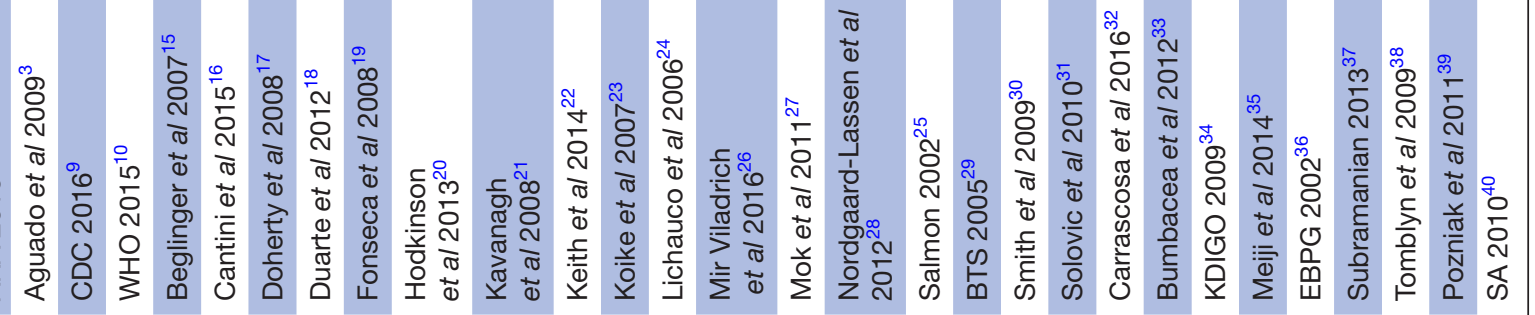




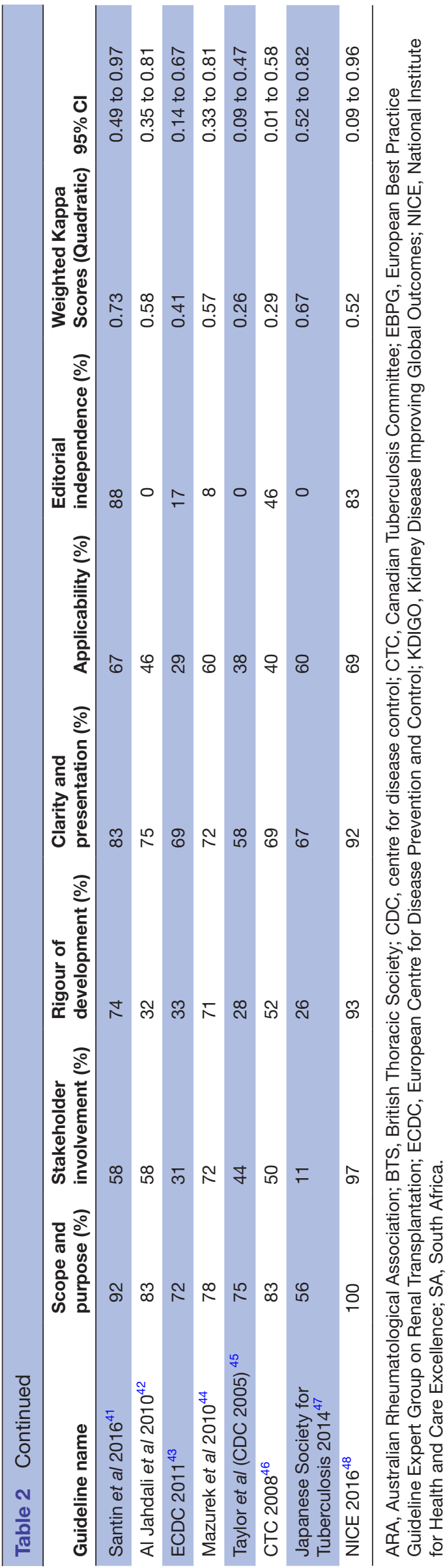

countries. ${ }^{10}$ Given the anticipated costs of IGRA, and the general acceptance of TST by clinicians and patients, TST was preferred in low income countries, despite the lower test accuracies of TST. ${ }^{10}$ In the high prevalence settings of South Africa and the Philippines, there was no reliable testing method: a combined TST and IGRA approach was recommended in one guideline, ${ }^{20}$ treatment of all patients with HIV without screening was recommended in another ${ }^{40}$ and TST alone in one guideline. ${ }^{24}$

\section{Defining screen positive and negative results}

Criteria for TST positivity varied across guidelines. Some recommended a TST-induced reaction of at least $5 \mathrm{~mm}$ diameter in all populations, to allow for the treatment of patients in high-risk settings. ${ }^{17} 19-212635-374048$ Other recommendations for the threshold diameter ranged from $6 \mathrm{~mm}$ to $20 \mathrm{~mm}{ }^{18-21232426273133}$ Where the TST result was initially negative, two guidelines recommended repeat testing. ${ }^{23} 45$ In all guidelines, an individual was deemed to be at risk for LTBI if either the TST or IGRA was positive.

\section{Are these recommendations valid?}

There is a body of evidence assessing the test performance characteristics of TST and IGRA in the general population. However, these recommendations were sourced largely from observational studies performed in middle to high-income countries and did not include immunosuppressed patients from low-resource settings and with low certainty of the evidence. Given the low test sensitivity of TST in immunosuppressed patients, some guidelines suggested a two-stage screening, first using TST and then IGRA to increase the detection rates of LTBI. ${ }^{1720303546}$ Among those who are immunosuppressed and had previously been vaccinated with BCG, IGRA generally performs better than TST. IGRA test sensitivity and specificity varies between $67 \%-75 \%$ and $93 \%-99 \%$, respectively. ${ }^{33}{ }^{43}$ However, given the concerns of spectrum bias, most guidelines suggested caution in the interpretation of test results among immunosuppressed hosts.

\section{Treatment for latent TB infection \\ Population of interests}

Either a positive TST or IGRA was considered sufficient evidence to warrant further evaluation. Prior to LTBI treatment, exclusion of active TB was recommended. ${ }^{1915171825262930323542-444748}$ Once active ТВ was excluded, LTBI treatment was recommended. Treatment for LTBI was also indicated for those who were BCG vaccinated, because BCG status may indicate time spent in an area with a high prevalence of LTBI. ${ }^{34}$ Furthermore, in South Africa, where there is a high prevalence of TB, treatment for LTBI was recommended in all patients after exclusion of active TB in the setting of HIV. ${ }^{40}$ Also, most clinical practice guidelines recommended LTBI treatment where clinical suspicion was high, regardless of the IGRA and TST test findings. ${ }^{1} 31519202426282933$ 35-38 
Table 3 Summary of recommendations

\begin{tabular}{|c|c|c|c|c|c|c|c|c|}
\hline \multirow[b]{2}{*}{ Guidelines } & \multirow[b]{2}{*}{ Population } & \multicolumn{2}{|c|}{$\begin{array}{l}\text { Screening } \\
\text { process }\end{array}$} & \multirow[b]{2}{*}{ IGRA } & \multirow[b]{2}{*}{ CXR } & \multirow{2}{*}{$\begin{array}{l}\text { Treatment } \\
\text { method }\end{array}$} & \multirow{2}{*}{$\begin{array}{l}\text { Treatment } \\
\text { duration }\end{array}$} & \multirow{2}{*}{$\begin{array}{l}\text { Timing before } \\
\text { immunosuppression }\end{array}$} \\
\hline & & History & $\overline{T S T}$ & & & & & \\
\hline ARA $2010^{1}$ & Biological therapy & & $\mathrm{x}$ & $x$ & $\mathrm{x}$ & Isoniazid* & $6-9$ months & $1-2$ months \\
\hline Aguado et al $2009^{3}$ & Transplant recipients & $\mathrm{x}$ & $x$ & & $x$ & Isoniazid & 9 months & Before transplant \\
\hline $\operatorname{CDC} 2016^{9}$ & Patients with HIV & & $x$ & $\mathrm{x}$ & & Isoniazid & 9 months & NS \\
\hline WHO $2015^{10}$ & $\begin{array}{l}\text { Low-middle income } \\
\text { countries }\end{array}$ & & $x$ & $x$ & & Isoniazid & 6 months & NS \\
\hline $\begin{array}{l}\text { Beglinger et al } \\
2007^{15}\end{array}$ & Biological therapy & $x$ & & $\mathrm{x}$ & $\mathrm{x}$ & $\begin{array}{l}\text { Isoniazid OR } \\
\text { rifampicin }\end{array}$ & NS & 1 month \\
\hline Cantini et al $2015^{16}$ & Biological therapy & $x$ & $x$ & $x$ & & Isoniazid & 9 months & 1 month \\
\hline Doherty $2008^{17}$ & Patients with psoriasis & $x$ & $x$ & & $\mathrm{x}$ & Isoniazid & 9 months & $1-2$ months or longer \\
\hline Duarte et al $2012^{18}$ & Biological therapy & $x$ & $x$ & $x$ & & Isoniazid & 9 months & $1-2$ months \\
\hline Fonseca et al $2008^{19}$ & Biological therapy & $x$ & $x$ & & $\mathrm{x}$ & Isoniazid & $6-9$ months & 1 month \\
\hline $\begin{array}{l}\text { Hodkinson } \\
\text { et al } 2013^{20}\end{array}$ & $\begin{array}{l}\text { Patients with } \\
\text { rheumatoid arthritis }\end{array}$ & $x$ & $x$ & $\mathrm{x}$ & $x$ & Isoniazid & 9 months & 1 month \\
\hline $\begin{array}{l}\text { Kavanagh } \\
\text { et al } 2008^{21}\end{array}$ & Biological therapy & $x$ & $x$ & & $x$ & Isoniazid & 9 months & Pre-immunosuppression \\
\hline Keith et al $2014^{22}$ & Bullous dermatosis & & $\mathrm{x}$ & $\mathrm{x}$ & & NS & NS & NS \\
\hline Koike et al $2007^{23}$ & Biological therapy & $\mathrm{x}$ & $x$ & & $x$ & Isoniazid & NS & NS \\
\hline $\begin{array}{l}\text { Lichauco et al } \\
2006^{24}\end{array}$ & Biological therapy & & $x$ & & $x$ & Isoniazid & 9 months & 1 month \\
\hline Salmon $2002^{25}$ & Biological therapy & & $x$ & & $x$ & $\begin{array}{l}\text { Rifampicin } \\
\text { and } \\
\text { pyrazinamide }\end{array}$ & 2 months & 3 weeks \\
\hline $\begin{array}{l}\text { Mir Viladrich } \\
\text { et al } 2016^{26}\end{array}$ & Biological therapy & $x$ & $x$ & $x$ & & Isoniazid & 9 months & 4 weeks \\
\hline Mok et al $2011^{27}$ & Biological therapy & & $x$ & & & Isoniazid & 9 months & 4 weeks \\
\hline $\begin{array}{l}\text { Nordgaard-Lassen } \\
\text { et al } 2012^{28}\end{array}$ & Biological therapy & & & $x$ & & Isoniazid & 9 months & 4 weeks \\
\hline BTS $2005^{29}$ & Biological therapy & $x$ & $x$ & & $x$ & Isoniazid & 6 months & Concurrent \\
\hline Smith et al $2009^{30}$ & Biological therapy & & & $\mathrm{x}$ & $x$ & $\begin{array}{l}\text { Isoniazid OR } \\
\text { Isoniazid and } \\
\text { rifampicin }\end{array}$ & $\begin{array}{l}6 \text { months } \\
\text { OR } \\
3 \text { months }\end{array}$ & 2 months \\
\hline Solovic et al $2010^{31}$ & Biological therapy & $x$ & $x$ & $x$ & $\mathrm{x}$ & Isoniazid & 9 months & 4 weeks \\
\hline $\begin{array}{l}\text { Carrasoca } \\
\text { et al } 2016^{32}\end{array}$ & Methotrexate therapy & & $\mathrm{x}$ & $x$ & $\mathrm{x}$ & Isoniazid & NS & NS \\
\hline $\begin{array}{l}\text { Bumbacea } \\
\text { et al } 2012^{33}\end{array}$ & Transplant recipients & & $x$ & $x$ & & NS & NS & Before transplant \\
\hline KDIGO $2009^{34}$ & Renal transplant & $x$ & $x$ & & & Isoniazid & 9 months & NS \\
\hline Meije et al $2014^{35}$ & Transplant recipients & & $x$ & $\mathrm{x}$ & & Isoniazid & 9 months & NS \\
\hline EBPG $2002^{36}$ & $\begin{array}{l}\text { Renal transplant } \\
\text { recipients }\end{array}$ & $x$ & $x$ & & $\mathrm{x}$ & Isoniazid & 9 months & NS \\
\hline Subramanian $2013^{37}$ & Transplant recipients & $x$ & $x$ & $x$ & $x$ & Isoniazid & 9 months & Before or after transplant \\
\hline Tomblyn et al $2009^{38}$ & SCT recipients & $x$ & $x$ & $x$ & & Isoniazid & 9 months & NS \\
\hline Pozniak et al $2011^{39}$ & Patients with HIV & & $x$ & $x$ & & Isoniazid & 6 months & NS \\
\hline SA $2010^{40}$ & Patients with HIV & & $x$ & & & Isoniazid & 6 months & NS \\
\hline \multirow[t]{3}{*}{ Santin et al $2017^{41}$} & Patients with HIV & $\mathrm{x}$ & $x$ & $\mathrm{x}$ & & NS & NS & NS \\
\hline & Biological therapy & $x$ & $x$ & $x$ & & NS & NS & NS \\
\hline & Transplant recipients & $\mathrm{x}$ & $\mathrm{x}$ & $\mathrm{x}$ & & NS & NS & NS \\
\hline
\end{tabular}




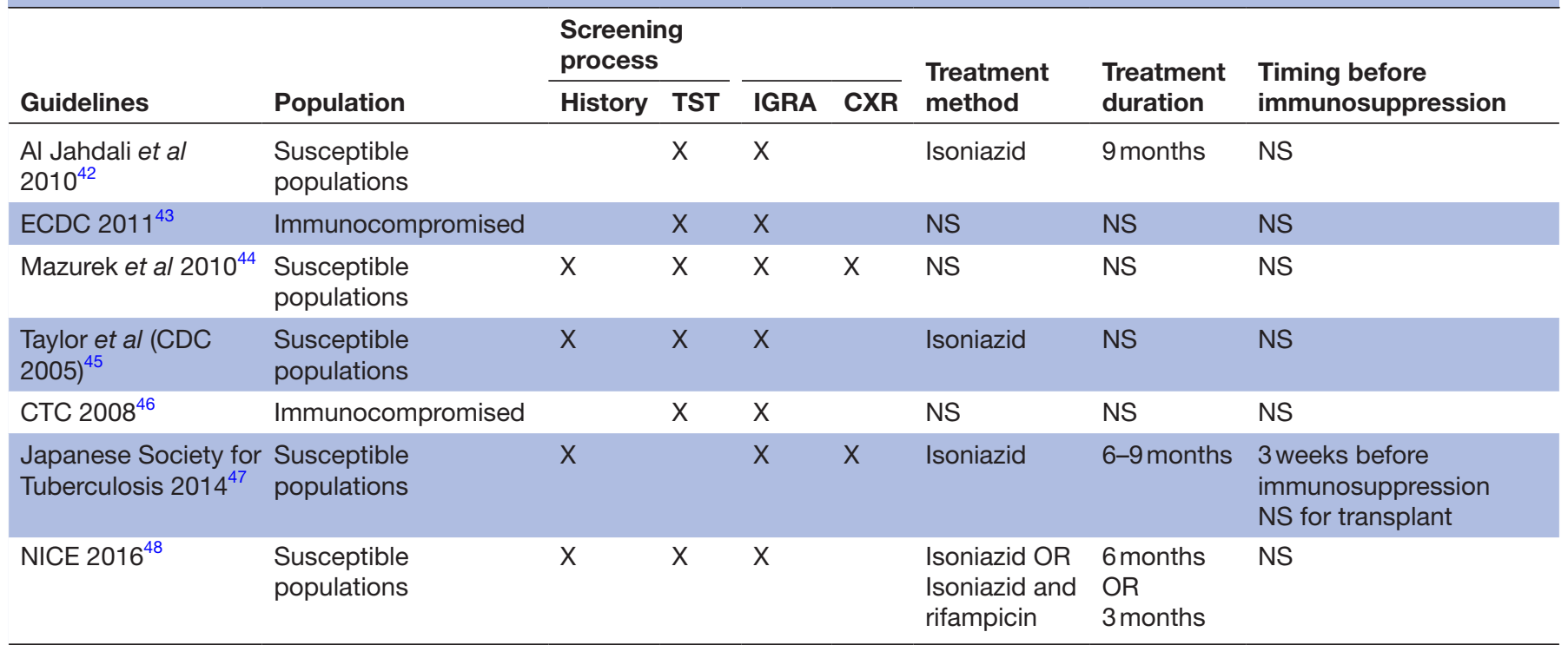

*Where isoniazid is used, it is always provided concurrently with pyridoxine prophylaxis.

ARA, Australian Rheumatological Association; BTS, British Thoracic Society; CDC, centre for disease control; CTC, Canadian Tuberculosis Committee; CXR, chest X-ray; EBPG, European Best Practice Guideline Expert Group on Renal Transplantation; ECDC, European Centre for Disease Prevention and Control; IGRA, interferon gamma release assay; KDIGO, Kidney Disease Improving Global Outcomes; NICE, National Institute for Health and Care Excellence; NS, not specified; SA, South Africa; SCT, Stem cell transplant, TST, tuberculin skin test.

\section{Intervention and duration}

Recommendations for the treatment of LTBI were largely similar across guidelines, regardless of the mode of immunosuppression. In most guidelines, isoniazid $300 \mathrm{mg}$ daily with pyridoxine was recommended for a duration of 9 months. ${ }^{3} 9$ 16-21 24-27 2931 33-39 42 Six months of isoniazid therapy was considered less efficacious, ${ }^{18}$ but was recommended in one guideline. ${ }^{48}$ Three guidelines suggested a flexible treatment regimen of 6-9 months of the combined therapies. ${ }^{19} 3047$ Four guidelines did not specify duration. ${ }^{15} 233245$

Rifamycin-based therapy $(10 \mathrm{mg} / \mathrm{kg} /$ day $)$ either alone or for three ${ }^{10}$ or four ${ }^{1391015-18242627313335-3942}$ months was the second most frequently reported treatment strategy among patients who tested positive for LTBI. This was thought to be useful when isoniazid was contraindicated or not tolerated, ${ }^{27}$ with one guideline describing the option as cheaper, but with more drug-drug interactions. ${ }^{18}$ Rifampicin plus isoniazid for three $\mathrm{e}^{11015-19252629-3139}$ or 4 months ${ }^{10} 24$ was also an option. Rifampicin plus isoniazid for 3 months was stipulated as a primary alternative therapy to isoniazid in two guidelines. ${ }^{30} 48$ Other options included rifabutin for 4 months ${ }^{92}$ or 3 months of weekly rifapentine and isoniazid. ${ }^{910}$ Finally, rifampicin and pyrazinamide for a shorter 2-month regimen was considered as an option in eight guidelines, ${ }^{3252935-39}$ with most being in the transplantation setting. The shorter duration of treatment was considered advantageous for those maintained on the transplant waiting list. ${ }^{3}{ }^{35-38}$ However, a biological therapy-based guideline advised against this option due to the increased risk of hepatotoxicity. ${ }^{24}$
In the transplantation and HIV settings, some guidelines specified avoidance of rifamycins, given the potential drug-drug interactions with calcineurin inhibitors and protease inhibitors. ${ }^{355}$ However, therapeutic drug monitoring may mitigate against the potential for such interactions. ${ }^{34}$ Several other non-rifamycin based alternatives were recommended and included ethambutol with levofloxacin or moxifloxacin for 6 months, ${ }^{3}{ }^{37} 12$ weeks of rifapentine and isoniazid and 6 months of isoniazid with ethambutol. ${ }^{24}$

Close monitoring with monthly liver function tests and for peripheral neuropathy was recommended while on treatment for all patients. ${ }^{39} 101718263135374047$ Coadministration of vitamin B6 (pyridoxine) was suggested universally, to reduce the risk of peripheral neuropathy associated with isoniazid. If there were treatment interruptions for more than 2 months, one guideline recommended clinical and radiological reassessment for TB. ${ }^{42}$

\section{Timing of preventive therapy}

In patients who are medically immunosuppressed, most guidelines recommended delaying medical therapy for 1 month after commencement of LTBI treatment where possible, to reduce the risk of TB reactivation. ${ }^{15-18} 20$ 24-28 Alternative waiting periods varied between 3 weeks ${ }^{25} 47$ to 2 months. ${ }^{30}$ One guideline preferred a prolonged delay, but did not provide a time frame. ${ }^{21}$ However, if the underlying disease was severe, earlier institution of immunosuppressive agents was accepted ${ }^{1729}$ once active TB was excluded. $^{28}$ 
In transplant setting, patients with LTBI are recommended to commence treatment on the waiting list where possible, with treatment ideally completed prior to transplantation. ${ }^{333353738}$ However, treatment interruption peritransplantation, with recommencement and completion of the treatment course once patients were clinically stable, may also be considered. ${ }^{33} 3537$ LTBI treatment should not delay transplantation. ${ }^{38}$ In the setting of liver transplantation, the use of anti-TB medications has been associated with increased risk of hepatotoxicity. Thus, it was generally recommended that LTBI therapy be commenced after transplantation, to avoid drug-related fulminant hepatitis while waiting for a donor organ. ${ }^{3} 3537$

In patients with HIV, the timing of commencement of antiretroviral therapy in relation to LTBI treatment was not specified by clinical practice guidelines. Unlike treatment for active TB, immune reconstitution related to LTBI treatment has not been documented..$^{9}$ Generally, it was recommended to initiate or continue antiretroviral treatment concurrently with treatment for LTBI. ${ }^{39} 40$

\section{Are these recommendations valid?}

Overall, clinical practice guidelines recommended the use of isoniazid-based or rifamycin-based regimes for the treatment of LTBI. The evidence for recommendations was largely sourced from observational studies in high-income countries, thus limiting the ability to generalise recommendations to low-income countries. There was very little evidence about the exact time frame of delay before initiating treatment. In addition, side effects associated with the treatment of LTBI, such as hepatotoxicity, neuropathy, gastrointestinal toxicity and rash, were discussed in only 50\% of the guidelines. ${ }^{1} 91018192124293133$ 35-373940 424748

\section{DISCUSSION}

Clinical practice guidelines for screening and treatment of LTBI vary in scope and their recommendations for screening modalities, frequency of screening and the target populations of interest. The two-stage screening approach of TST and IGRA was most frequently recommended because of improved test performance characteristics in high risk, immunosuppressed populations. Guidelines did not specify how to interpret a mismatch in results between TST and IGRA, but recommended treatment where either test was positive. For treatment, most recommendations suggested the use of isoniazid-based therapies for LTBI, but there were discrepancies in the duration and timing of commencing treatment. Nine months of isoniazid-based therapy appeared to be the preferred therapy for LTBI, and most agreed that treatment of LTBI should be initiated prior to commencement of immunosuppressive therapies.

While most guidelines conducted a comprehensive literature review, the evidence base supporting the recommendations was limited to observational studies without trial-based evidence to support routine screening and treatment for LTBI in immunosuppressed patients. The rigour of guideline development lacks robustness. Less than half of the guidelines provided grading of the evidence and recommendations. Details regarding the methods used for formulating the recommendations were not adequately described, lacking transparency in the methodology and did not consistently link the recommendations to the corresponding level of evidence, both for screening and treatment of LTBI and the benefit-harm-cost relationship.

In this review, we found that public and stakeholder consultation was rarely reported in the development of the guidelines. Only 22\% underwent a peer review process and $11 \%$ underwent public consultation. Engaging experts may improve guidelines by allowing criticism and suggestions. ${ }^{19}$ Expert clinicians were consulted in guideline development and included clinicians such as rheumatologists, gastroenterologists, dermatologists, thoracic physicians, infectious diseases physicians and clinicians involved in treating patients with HIV. Public consultations and patient participation can also improve guideline applicability. ${ }^{49}$ Although four guidelines used public consultation, none elaborated on how they have contributed to guideline development. Guideline applicability may be improved by active consumer involvement and engagement in the development, design and implementation process.

Inconsistencies exist in the recommendations for screening modalities and frequencies for LTBI. The TST evokes delayed hypersensitivity after intradermal application of a purified protein derivative. ${ }^{33}$ TST generally performs poorly in immunosuppressed patients, with reported estimates of $89 \%$ and $71 \%$ for test sensitivity and specificity, respectively. ${ }^{43}$ The lower test specificity may be due to the cross-reactivity with prior BCG vaccination ${ }^{15} 34$ and infections with non-TB mycobacteria. Testing with IGRA identifies adaptive immune response to TB-specific antigens which are not present in BCG strains, enabling greater specificity. ${ }^{43}$ Test sensitivity of TST and IGRA is uncertain or may be reduced among immunosuppressed hosts because of anergy. ${ }^{33}$ Determining the diagnostic accuracy of the IGRA and TST is complicated because of the absence of an accurate and valid reference standard. For example, underestimation of the true test sensitivity and specificity of the new test may occur if the imperfect reference incorrectly classifies those with disease as no disease (false negative) and those without disease as disease (false positive).

Multiple diagnostic algorithms for LTBI have been proposed to overcome the shortcomings of IGRA and TST, including the use of predefined multiple imperfect diagnostic tests and clinical data to inform the prevalence estimates of LTBI in different settings. Despite this, prevalence of LTBI varies substantially, even in high-risk patients. ${ }^{50}$ Statistical methods such as latent class and Bayesian mixture analyses may overcome this limitation. ${ }^{51} 52$

Most guidelines recommended treatment for LTBI, including those who were screened negative but of high clinical risk. While this is of relevance and importance to at-risk immunosuppressed patients, interventions such 
as isoniazid and alternatives including rifampicin are not without adverse complications. No guidelines specified contraindications to treatment, except in the case of liver transplantation, where treatment was recommended to be delayed until after transplantation due to the increased risk of hepatotoxicity. ${ }^{35} 37$ Treatment of LTBI also has other potential drug toxicities, including neuropathy and drug-drug interactions, particularly for rifampicin-based regimens. Although many guidelines acknowledged these toxicities, the impact of overtreatment and the potential risk of adverse drug reactions were not quantified. Only two guidelines specified the growing concern of increasing rates of multidrug-resistant TB secondary to excess exposure to drug therapy ${ }^{2347}$ Furthermore, barriers to screening and treatment are only considered in one guideline, which stated that there were no barriers in a public hospital. ${ }^{41}$ This therefore would not apply in under-resourced settings or where public healthcare is not available.

In our systematic review, we used a reliable and validated method using the AGREE II to assess guidelines for the screening for and treatment of LTBI. There was good agreement between the two reviewers. We have summarised the variability in the literature pertaining to LTBI, allowing for a consolidated approach to recommendations for screening and management of LTBI. However, limitations of our review are that we have only included guidelines written in the English language. Therefore, applicability of our findings to other settings, particularly those in low-income countries are uncertain. Future guidelines should consider the specific health issues that are applicable to the population of interest, such as in low-income settings, and consider cost implications and barriers to screening and treatment. Very few guidelines discussed non-TNF based immunosuppression. This included two well-established medications-methotrexate and cyclophosphamide-for the management of autoimmune disease as well as newer biological treatments. ${ }^{17}$ Only one guideline included newer monoclonal agents ${ }^{30}$ and one for patients on regular methotrexate therapy. ${ }^{32}$ One of the key challenges for guideline developers is the translation and dissemination of these recommendations in clinical practice, which may transform care and improve health of the target population. Currently, there are limited training initiatives in the implementation of these guidelines in different cultural and resource settings. Future research, through direct engagement with local stakeholders, clinicians and patients should therefore assess the features and processes that underpin success in research translation and adapt these strategies in practice.

Overall, the current clinical guidelines reaffirm the importance of LTBI screening and treatment. Although there are some discrepancies in terms of screening modalities, recommendation for the treatment of LTBI was consistent across all guidelines. Quality of evidence and rigour of guideline development varied. Therefore, there is a need to undertake better-quality studies, with international, multidisciplinary and stakeholder involvement to consolidate current evidence. This is critical to support evidence-based guidelines development and patient-centred practice to improve patient outcomes.

\section{Author affiliations}

${ }^{1}$ Centre for Infectious Diseases and Microbiology, Westmead Hospital, Westmead, New South Wales, Australia

${ }^{2}$ Centre for Transplant and Renal Research, Westmead Hospital, Westmead, New South Wales, Australia

${ }^{3}$ School of Medicine, The University of Sydney, Sydney, New South Wales, Australia ${ }^{4}$ Centre for Kidney Research, The Children's Hospital, Westmead, New South Wales, Australia

${ }^{5}$ Sydney School of Public Health, The University of Sydney, Sydney, New South Wales, Australia

Contributors TH: database search, selection of guidelines; grading of guidelines, assessing quality, interpretation; preparation of manuscript and editing. EA: selection of guidelines; grading of guidelines, assessing quality, interpretation; preparation of manuscript and editing. SC, AT, GW: preparation of manuscript and editing.

Funding The authors have not declared a specific grant for this research from any funding agency in the public, commercial or not-for-profit sectors.

Competing interests SC reports grants from MSD Australia, outside the submitted work.

Patient consent Not required.

Provenance and peer review Not commissioned; externally peer reviewed.

Data sharing statement Data are available on request.

Open access This is an open access article distributed in accordance with the Creative Commons Attribution Non Commercial (CC BY-NC 4.0) license, which permits others to distribute, remix, adapt, build upon this work non-commercially, and license their derivative works on different terms, provided the original work is properly cited, appropriate credit is given, any changes made indicated, and the use is non-commercial. See: http://creativecommons.org/licenses/by-nc/4.0/.

\section{REFERENCES}

1. Australian Rheumatology Association. Screening for latent tuberculosis infection (LTBI) prior to use of biological agents in Australia. 2010. https://rheumatology.org.au/downloads/April2010FINAL-SCREENINGFORLATENTTUBERCULOSISINFECTION.pdf (accessed 25 Oct 2016).

2. Gómez-Reino JJ, Carmona L, Valverde VR, et al. Treatment of rheumatoid arthritis with tumor necrosis factor inhibitors may predispose to significant increase in tuberculosis risk: a multicenter active-surveillance report. Arthritis Rheum 2003;48:2122-7.

3. Aguado JM, Torre-Cisneros J, Fortún J, et al. Tuberculosis in solidorgan transplant recipients: consensus statement of the group for the study of infection in transplant recipients (GESITRA) of the Spanish Society of Infectious Diseases and Clinical Microbiology. Clin Infect Dis 2009;48:1276-84.

4. Budak-Alpdogan T, Tangün $Y$, Kalayoglu-Besisik $S$, et al. The frequency of tuberculosis in adult allogeneic stem cell transplant recipients in Turkey. Biol Blood Marrow Transplant 2000;6:370-4.

5. Askling J, Fored CM, Brandt L, et al. Risk and case characteristics of tuberculosis in rheumatoid arthritis associated with tumor necrosis factor antagonists in Sweden. Arthritis Rheum 2005;52:1986-92.

6. Carmona L, Gómez-Reino JJ, Rodríguez-Valverde V, et al. Effectiveness of recommendations to prevent reactivation of latent tuberculosis infection in patients treated with tumor necrosis factor antagonists. Arthritis Rheum 2005;52:1766-72.

7. Tubach F, Salmon D, Ravaud P, et al. Risk of tuberculosis is higher with anti-tumor necrosis factor monoclonal antibody therapy than with soluble tumor necrosis factor receptor therapy: the three-year prospective French research axed on tolerance of biotherapies registry. Arthritis Rheum 2009;60:1884-94.

8. Wolfe F, Michaud K, Anderson J, et al. Tuberculosis infection in patients with rheumatoid arthritis and the effect of infliximab therapy. Arthritis Rheum 2004;50:372-9.

9. Panel on Opportunistic Infections in HIV-Infected Adults and Adolescents. Guidelines for the prevention and treatment of opportunistic infections in HIV-infected adults and adolescents: recommendations from the Centers for Disease Control and 
Prevention, the National Institutes of Health, and the HIV Medicine Association of the Infectious Diseases Society of America. 2016 https://aidsinfo.nih.gov/contentfiles/lvguidelines/adult_oi.pdf (accessed 27 Oct 2016).

10. World Health Organization. Guidelines on the management of latent tuberculosis infection. Geneva: World Health Organization, 2015.

11. Kong FS, Tomford JW, Teixeira L, et al. Challenges of interferon- $\gamma$ release assay conversions in serial testing of health-care workers in a TB control program. Chest 2011;142:55-62.

12. Slater M, Parsonnet J, Banaei N. Investigation of false-positive results given by the QuantiFERON-TB Gold In-Tube assay. J Clin Microbiol 2012;50:3105-7.

13. Field MJ, Lohr KN. Committee to Advise the Public Health Service on Clinical Practice Guidelines, Institute of Medicine. Clinical practice guidelines: directions of a new program. Washington, DC: National Academy Press, 1990.

14. Brouwers MC, Kho ME, Browman GP, et al. AGREE II: advancing guideline development, reporting and evaluation in health care. CMAJ 2010;182:E839-42.

15. Beglinger C, Dudler J, Mottet C, et al. Screening for tuberculosis infection before the initiation of an anti-TNF-alpha therapy. Swiss Med Wkly 2007;137:620-2.

16. Cantini F, Nannini C, Niccoli L, et al. Guidance for the management of patients with latent tuberculosis infection requiring biologic therapy in rheumatology and dermatology clinical practice. Autoimmun Rev 2015;14:503-9.

17. Doherty SD, Van Voorhees A, Lebwohl MG, et al. National Psoriasis Foundation consensus statement on screening for latent tuberculosis infection in patients with psoriasis treated with systemic and biologic agents. J Am Acad Dermatol 2008;59:209-17.

18. Duarte R, Campainha S, Cotter J, et al. Position paper on tuberculosis screening in patients with immune mediated inflammatory diseases candidates for biological therapy. Acta Reumatol Port 2012;37:290-9.

19. Fonseca JE, Lucas $\mathrm{H}$, Canhão $\mathrm{H}$, et al. Recommendations for the diagnosis and treatment of latent and active tuberculosis in inflammatory joint diseases candidates for therapy with tumor necrosis factor alpha inhibitors - March 2008 update. Rev Port Pneumol 2008;14:271-83.

20. Hodkinson B, Van Duuren E, Pettipher C, et al. South African recommendations for the management of rheumatoid arthritis: an algorithm for the standard of care in 2013. S Afr Med J 2013;103(8 Pt 2):576-85.

21. Kavanagh PM, Gilmartin JJ, O'Donnell J, et al. Tumour necrosis factor-alpha and tuberculosis: guidance from the National TB Advisory Committee. Ir Med J 2008;101:6-7.

22. Keith PJ, Wetter DA, Wilson JW, et al. Evidence-based guidelines for laboratory screening for infectious diseases before initiation of systemic immunosuppressive agents in patients with autoimmune bullous dermatoses. Br J Dermatol 2014;171:1307-17.

23. Koike R, Takeuchi T, Eguchi K, et al. Update on the Japanese guidelines for the use of infliximab and etanercept in rheumatoid arthritis. Mod Rheumatol 2007:17:451-8.

24. Lichauco JJT, Tankeh-Torres SA, Navarra SV, et al. Philippine guidelines on the screening for tuberculosis prior to the use of biologic agents. APLAR Journal of Rheumatology 2006;9:184-92.

25. Salmon D. Recommendations about the prevention and management of tuberculosis in patients taking infliximab. Joint, Bone. Spine 2002;69:170-2.

26. Mir Viladrich I, Daudén Tello E, Solano-López G, et al. Consensus document on prevention and treatment of tuberculosis in patients for biological treatment. Arch Bronconeumol 2016;52:36-45.

27. Mok CC, Tam LS, Chan TH, et al. Management of rheumatoid arthritis: consensus recommendations from the Hong Kong Society of Rheumatology. Clin Rheumatol 2011;30:303-12.

28. Nordgaard-Lassen I, Dahlerup JF, Belard E, et al. Guidelines for screening, prophylaxis and critical information prior to initiating antiTNF-alpha treatment. Dan Med J 2012;59:C4480.

29. British Thoracic Society Standards of Care Committee. BTS recommendations for assessing risk and for managing Mycobacterium tuberculosis infection and disease in patients due to start anti-TNF-alpha treatment. Thorax 2005;60:800-5.

30. Smith $\mathrm{CH}$, Anstey AV, Barker JN, et al. British Association of Dermatologists' guidelines for biologic interventions for psoriasis 2009. Br J Dermatol 2009;161:987-1019.

31. Solovic I, Sester M, Gomez-Reino JJ, et al. The risk of tuberculosis related to tumour necrosis factor antagonist therapies: a TBNET consensus statement. Eur Respir J 2010;36:1185-206.
32. Carrascosa JM, de la Cueva P, Ara M, et al. Methotrexate in moderate to severe psoriasis: review of the literature and expert recommendations. Actas Dermosifiliogr 2016;107:194-206.

33. Bumbacea D, Arend SM, Eyuboglu F, et al. The risk of tuberculosis in transplant candidates and recipients: a TBNET consensus statement. Eur Respir J 2012;40:990-1013.

34. Kidney Disease: Improving Global Outcomes (KDIGO) Transplant Work Group. KDIGO clinical practice guideline for the care of kidney transplant recipients. Am J Transplant 2009;9(Suppl 3):S1-155.

35. Meije Y, Piersimoni C, Torre-Cisneros J, et al. Mycobacterial infections in solid organ transplant recipients. Clin Microbiol Infect 2014;20(Suppl 7):89-101.

36. EBPG Expert Group on Renal Transplantation. European best practice guidelines for renal transplantation. Section IV: Longterm management of the transplant recipient. IV.10. Pregnancy in renal transplant recipients. Nephrol Dial Transplant 2002;17(Supp 4):50-5.

37. Subramanian AK, Morris MI. AST Infectious Diseases Community of Practice. Mycobacterium tuberculosis infections in solid organ transplantation. Am J Transplant 2013;13(Suppl 4):68-76.

38. Tomblyn M, Chiller T, Einsele H, et al. Guidelines for preventing infectious complications among hematopoietic cell transplantation recipients: a global perspective. Biol Blood Marrow Transplant 2009;15:1143-238.

39. Pozniak AL, Coyne KM, Miller RF, et al. British HIV Association guidelines for the treatment of TB/HIV coinfection 2011. HIV Med 2011:12:517-24.

40. Republic of South Africa Department of Health. Guidelines for tuberculosis preventive therapy among HIV infected individuals in South Africa. 2010 www.who.int/hiv/pub/guidelines/south africa_hiv tb.pdf (accessed 1 Nov 2016).

41. Santin M, García-García J-M, Domínguez J. Guidelines for the use of interferon- $\gamma$ release assays in the diagnosis of tuberculosis infection. Enfermedades Infecciosas y Microbiología Clínica 2016;34:303. e1-303.e13.

42. Al Jahdali HH, Baharoon S, Abba AA, et al. Saudi guidelines for testing and treatment of latent tuberculosis infection. Ann Saudi Med 2010;30:38-49.

43. European Centre for Disease Prevention and Control. Use of interferon-gamma release assays in support of TB diagnosis. Stockholm: European Centre for Disease Prevention and Control (ECDC), 2011.

44. Mazurek GH, Jereb J, Vernon A, et al. Updated guidelines for using interferon gamma release assays to detect mycobacterium tuberculosis infection - United States, 2010. MMWR Recomm Rep 2010;59(RR-5):1-25.

45. Taylor Z, Nolan CM, Blumberg HM. American Thoracic SocietyCenters for Disease Control and Preventionlnfectious Diseases Society of America. Controlling tuberculosis in the United States. Recommendations from the American Thoracic Society, CDC, and the Infectious Diseases Society of America. MMWR Recomm Rep 2005;54(RR-12):1-81.

46. Canadian Tuberculosis Committee. Updated recommendations on interferon gamma release assays for latent tuberculosis infection. An Advisory Committee Statement (ACS). Can Commun Dis Rep 2008;34(Acs-6):1-13.

47. Prevention Committee of the Japanese Society for TuberculosisTreatment Committee of the Japanese Society for Tuberculosis. Treatment guidelines for latent tuberculosis infection. Kekkaku 2014;89:21-37.

48. National Collaborating Centre for Chronic Conditions (UK): Centre for Clinical Practice at NICE (UK). Tuberculosis: prevention, diagnosis, management and service organisation. London: National Institure for Health and Clinical Excellence (UK), 2016.

49. Krahn M, Naglie G. The next step in guideline development: incorporating patient preferences. JAMA 2008;300:436.

50. Pai M, Gokhale K, Joshi R, et al. Mycobacterium tuberculosis infection in health care workers in rural India: Comparison of a whole blood interferon- $\gamma$ assay with tuberculin skin testing. JAMA 2005;22:293-302.

51. Pai M, Dendukuri N, Wang L, et al. Improving the estimation of tuberculosis infection prevalence using T-cell-based assay and mixture models. Int J Tuberc Lung Dis 2008;12:895-902.

52. Doan TN, Eisen DP, Rose MT, et al. Interferon-gamma release assay for the diagnosis of latent tuberculosis infection: A latent-class analysis. PLoS One 2017;12:e0188631. 